
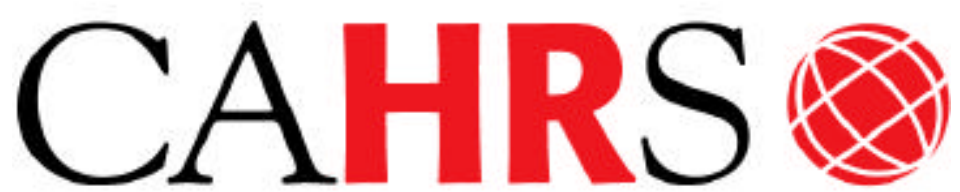

Center for Advanced Human Resource Studies
CAHRS / Cornell University 187 Ives Hall

Ithaca, NY 14853-3901 USA

Tel. 607 255-9358

www.ilr.cornell.edu/CAHRS/

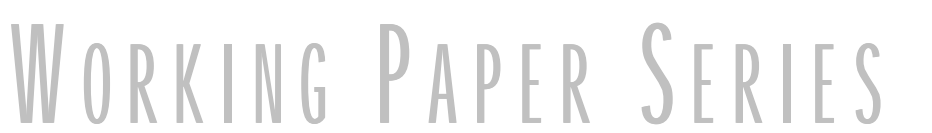

\title{
Toward a Unifying Framework for Exploring Fit and Flexibility in Strategic Human Resource Management
}

Scott A. Snell

Patrick M. Wright

Working Paper 97 - 13 


\title{
Toward a Unifying Framework for Exploring
}

\section{Fit and Flexibility in Strategic Human Resource Management}

\author{
Patrick M. Wright \\ School of Industrial and Labor Relations \\ 393 Ives Hall \\ Cornell University \\ Ithaca, NY 14853-3901 \\ Scott A. Snell \\ Department of Management \\ Pennsylvania State University \\ University Park, PA 16802 \\ Working Paper 97-13 \\ http://www.ilr.cornell.edu/cahrs
}

This paper has not undergone formal review or approval of the faculty of the ILR School. It is intended to make results of Center research available to others interested in preliminary form to encourage discussion and suggestions. 


\title{
Toward a Unifying Framework for Exploring
}

\section{Fit and Flexibility in Strategic Human Resource Management}

\begin{abstract}
This paper presents a framework for studying the concepts of fit and flexibility in the field of Strategic Human Resource Management (Strategic HRM) focusing on HRM practices, employee skills, and employee behaviors and reviews past conceptual and empirical work within that framework. A model of Strategic HRM is presented and this model is used to explore the concepts of fit and flexibility as they apply to Strategic HRM. The concepts of resource and coordination flexibility are applied to Strategic HRM, and the implications of the framework for both the practice of and research on Strategic HRM are discussed.
\end{abstract}

The authors wish to thank Barry Gerhart, Lee Dyer, and three anonymous reviewers for their comments on an earlier draft of this paper. Please send all correspondence concerning this manuscript to: Patrick M. Wright, School of Industrial and Labor Relations, 393 Ives Hall, Cornell University, Ithaca, NY 14853-3901, (607) 255-3429. 


\section{Fit and Flexibility in Strategic Human Resource Management}

The elevation of domestic and global competition has forced firms to examine all resources at their disposal in order to gain competitive advantage (Barney, 1991; Hamel and Prahalad, 1994). Not surprisingly, attention to the competitive potential of the employees or human resources has increased substantially (Huselid, 1995; Lado \& Wilson, 1984; Miles \& Snow, 1984; Schuler \& MacMillan, 1984; Wright, McMahan, \& McWilliams, 1994).

The field of Strategic Human Resource Management (Strategic HRM) focuses specifically on the role of human resources in improving firm performance or competitive advantage. Wright \& McMahan (1992) defined Strategic HRM as "the pattern of planned human resource deployments and activities intended to enable the firm to achieve its goals," (p. 298). This definition emphasizes congruence or fit between HR and strategy. In fact, they argued that HR fit consists of two types. First, vertical fit involves the alignment of human resource management (HRM) practices and the strategic management process of the firm (Schuler \& Jackson, 1987). Second, horizontal fit implies a congruence among the various HRM practices (Baird \& Meshoulam, 1988). Achievement of horizontal fit is viewed as instrumental for efficiently allocating human resources. Vertical fit, in turn, is viewed as directing those resources toward the primary initiatives of the organization.

Despite the pervasive discussions of fit, emphasis has increasingly been placed on the concept of flexibility in Strategic HRM (Kerr \& Jackofsky, 1989; Lengnick-Hall \& Lengnick-Hall, 1988; Milliman, Von Glinow, \& Nathan, 1991). Researchers in the area of Strategic HRM advocate that in the current complex and dynamic environment, organizations require flexibility to adapt to the diverse and changing requirements (Snow \& Snell, 1993). From this perspective, Strategic HRM is primarily concerned with developing the organizational capability to adapt to changing environmental contingencies (Snell, Youndt \& Wright, 1996).

At first glance, it might appear that the desirability of strategic fit and the need for organizational flexibility are in conflict. Indeed, the relationship between fit and flexibility in the context of Strategic HRM is not well understood, and little agreement exists regarding the definitions and value of each. The purpose of this paper is to present a framework which provides a theoretical foundation for understanding the strategic role of human resources in organizations through both fitting important aspects of the HR system to the strategic needs of the firm and building these components so as to enable flexible response to a variety of strategic requirements.

In order to do so, the paper will first examine the concepts of fit and flexibility and their relationship to one another. We will then explore the past conceptulizations of fit in Strategic 
HRM relative to HRM practices, employee skills, and employee behaviors. Based on this work, we propose a model of Strategic HRM which includes both fit and flexibility components. The paper will then examine the concept of flexibility in Strategic HRM, and explore the factors that can promote and/or impede achieving flexibility. Finally, the implications for Strategic HRM practice and research will be discussed.

\section{The Constructs of Fit and Flexibility Fit}

The concept of fit has served as the foundation of much theory building in organizational research. Numerous theories at the individual, group, and organizational levels of analysis postulate relationships among variables using terms such as fit, congruence, matched with, dependent upon, or consistent with. However, often these "fit" relationships are not well specified nor is the concept of fit well defined within the theoretical model (Venkatraman, 1989).

Nadler and Tushman (1980) defined congruence or fit as "the degree to which the needs demands, goals, objectives and/or structure of one component are consistent with the needs, demands, goals, objectives, and/or structure of another component," (p. 40). Inherent in all of the treatments of fit is the idea that organizations are more efficient and/or effective when they achieve fit relative to when a lack of fit exists (Baird \& Meshoulam, 1988; Lengnick-Hall \& Lengnick-Hall, 1988; Milliman, et al., 1991; Montemayor, 1996; Nadler \& Tushman, 1980; Venkatraman, 1989).

\section{Flexibility}

Strategic flexibility has been defined as "a firm's abilities to respond to various demands from dynamic competitive environments," (Sanchez, 1995: 138). Flexibility provides organizations with the ability to modify current practices in response to nontransient changes in the environment. Weick (1979) argues that flexibility requires detecting changes in the environment and retaining a sufficient pool of novel actions so that these changes can be accommodated. In contrast, Teece, Pisano, and Shuen described the need for firms in dynamic environments to "...reconfigure the firm's asset structure, and to accomplish the necessary internal and external transformations." (1997: 520). They refer to high flexibility firms as those with a capability to "...scan the environment, evaluate markets and competitors, and to quickly accomplish reconfiguration and transformation ahead of competition. (1997: 520) Thus, numerous authors have proposed that in dynamic or uncertain environments, flexibility promotes organizational effectiveness and survival (Chakravarthy, 1982; Miles \& Snow, 1978; Weick, 1979). 


\section{Fit vs. Flexibility or Fit and Flexibility}

Milliman et al. (1991) proposed that two relationships between fit and flexibility have been set forth in the Strategic HRM literature. One view, the "orthogonal" perspective, argues that fit and flexibility are opposite ends of the same continuum. For example, Lengnick-Hall and Lengnick Hall stated that "Research has shown that achieving fit is not always desirable. Further, a focus on maximizing fit can be counterproductive if organization change is needed or if the firm has adopted conflicting competitive goals to correspond to a complex competitive environment." (1988: 460). Thus, while not specifically proposing a negative relationship between fit and flexibility, these authors imply that the two cannot exist simultaneously.

The second view of the fit/flexibility relationship proposes that these variables are independent of one another, and Milliman et al. (1991) refer to this as the "complementary" perspective. This view argues that both concepts are essential for organizational effectiveness as the strategic management challenge is to cope with change (requiring flexibility) by continually adapting to achieve a fit between the firm and its external environment (Chakravarthy, 1982; Miles \& Snow, 1984).

Milliman et al. (1991) note that the differences between these two perspectives might stem from differences regarding the time frame and from differences regarding the goals of the research. In terms of the time frame, researchers advocating the orthogonal view are concerned with firms at one point in time, and argue both fit and flexibility cannot exist simultaneously, whereas advocates of the complementary view look at fit over a longer time horizon and explore adaptation processes. Regarding the goals of research, advocates of the orthogonal view are concerned with description (what firms actually do) whereas advocates of the complementary view seek to provide prescription (what firms ought to do).

Consistent with Milliman et al (1991), we propose that fit and flexibility are complementary, particularly because they focus on different aspects of organizations. Fit can be viewed as a state which exists at some level at a given point in time and because of its focus on an interface between two variables, has both internal (HR aspects) and external (strategy) components. Because fit deals with relationships among some set of dynamic contingent constructs, it can only be assessed as a snapshot; fit at time 1 in no way guarantees fit at time 2. This is why researchers interested in fit focus on a particular point in time (Milliman, et al., 1991).

Flexibility, on the other hand, is not a temporary state, but an actual characteristic (e.g., a trait) of an organization. Note that most definitions of flexibility refer to an "ability" to meet a variety of needs in a dynamic environment (e.g., Sanchez, 1995). In contrast to fit's focus on an 
interface of two variables, one internal and one external, flexibility is viewed as being purely internal in orientation. Flexibility is comprised of firm characteristics such as broad, heterogeneous skills/competencies of the workforce, organic administrative systems, etc. that enable a firm to adapt to some change in the environment (Chakravarthy, 1982). In essence, treatments of flexibility have focused on variety, malleability, or both.

Although flexibility is a characteristic that theoretically can be assessed at any point in time, it is more frequently assessed only over time. This is because while certain characteristics of the firm that comprise flexibility can be assessed at time 1, confirmatory evidence that flexibility existed at time 1 is best obtained by observing a successful adaptation to an environmental change at time 2 . Thus, flexibility is defined as the ability to achieve fit under a variety of environmental demands (Milliman et al., 1991). In contrast to the orthogonal view, this view proposes that fit and flexibility can exist at the same time.

Note that this treatment of fit and flexibility distinguishes the concepts as completely independent of one another. Fit does not equal inflexibility; similarly, misfit cannot be equated with flexibility. Flexibility is a characteristic of the firm which enables it to achieve a state of fit at any given point in time.

Consequently, in our view, the primary role of Strategic HRM should be to promote a fit with the demands of the competitive environment. In a stable, predictable environment, this might be efficiently achieved by using bureaucratic systems which focus on developing a human capital pool with a narrow range of skills and HR systems which elicit a narrow range of employee behavior. In this case, once fit is achieved, flexibility becomes relatively unimportant. However, today most firms face environments characterized by increasing dynamism and competition. In such a case, sustainable fit can only be achieved by developing a flexible organization. Thus, Strategic HRM must increasingly promote organizational flexibility in order for the firm to achieve a dynamic fit.

\section{Fit and Strategic HRM}

\section{Conceptualizations of Fit in Strategic HRM}

To examine the concept of fit in Strategic HRM, we should look at what researchers/writers have argued needs to be "fitted." Within the Strategic HRM literature, a variety of variables are proposed to require fit with firm strategy. This literature has not been completely consistent in specifying the combinations of variables among which fit will be advocated. As is discussed below, a review of this literature reveals that three generic conceptual variables requiring fit with strategy have been advanced by Strategic HRM 
researchers. These include fit between business strategy and HRM practices, employee skills, and employee behaviors.

Strategy - HRM Practices Fit. The first linkage proposed in Strategic HRM requires fit between a firm's strategy and its HRM practices. For example, Schuler and Jackson (1987) proposed that firms have at their disposal a "menu" of HR practices. Different firm strategies require different role behaviors from employees, and thus, the HRM practices are chosen based on their ability to elicit the behaviors required to implement a chosen strategy. Similarly, Miles and Snow (1984) discussed the differences in HR practices that would be observed between Defender, Prospector, and Analyzer strategic types. Wright and Snell (1991) noted that both the firm's strategic type and the directional strategy (retrenchment, growth, etc.) would influence the choice of sets of HRM practices.

In addition, empirical work has explored the Strategy - HRM Practices fit. Jackson, Schuler, \& Rivero (1989) examined differences in HRM practices associated with a variety of variables such as industry, manufacturing technology, and differentiation through innovation as a strategy. They found differences in a number of HR practices across business strategies.

Recently, Huselid (1995) explored the extent to which fit between strategy and HR practices influenced firm performance, and found no evidence that it did. Delery and Doty (1996) found only limited support for a fit between strategy and HR practices. Youndt, Snell, Dean and Lepak (1996) found significant support for fit, as fit between manufacturing strategy and human resource practices resulted in higher performance among a sample of manufacturing plants.

Strategy - Employee Skills Fit. The second linkage examined in Strategic HRM has been a fit between a firm's strategy and skills or characteristics of various employees. Many prescriptions regarding the match between Chief Executive Officers and General Managers have been proposed (e.g., Gerstein \& Reisman, 1983; Gupta, 1984; Hambrick \& Mason, 1984; Kerr, 1982; Olian \& Rynes, 1984) based on the assumption that "...different strategies require different types of people...for effective performance." (Olian \& Rynes, 1984: 171).

In addition, much of the empirical work on fit has examined the strategy - skill linkage. Gupta and Govindarajan (1984) found that manager's willingness to take risk and tolerance for ambiguity was positively related to firm performance for firms with a build strategy, but negatively related for firms with a harvest strategy. In addition, numerous researchers (Bantel and Jackson, 1989; Hitt \& Tyler, 1992; Michel and Hambrick, 1992; Wiersma \& Bantel, 1992) have empirically demonstrated the association between managerial characteristics and corporate level strategies such as diversification and restructuring. 
This linkage has also been explored at the level of the skills of the entire human capital pool (as opposed to just top managers). Lengnick-Hall \& Lengnick-Hall (1988) labeled one dimension of their matrix as "Organizational Readiness" which described the extent to which the firm's human resources possessed the skills, numbers, experience, and style necessary to implement the strategy. In an empirical study, Wright, et al. (1995) found that among NCAA Men's basketball teams, the relationship between certain skills of the team and the team's performance differed across the various strategies.

Strategy - Employee Behavior Fit. Finally, some researchers in Strategic HRM have called for a fit between a firm's strategy and the types of behaviors exhibited by employees. Schuler and Jackson's (1987) basic premise behind the "behavioral perspective" was that different strategies call for different role behaviors. For example, firms implementing a differentiation strategy require relatively repetitive and predictable behaviors, autonomous activity, and low risk taking activity, whereas those implementing an innovation strategy require high degrees of creative behavior, cooperative behavior, and risk taking.

The distinction between behaviors and skills is illustrated by Kerr \& Jackofsky (1989) in their discussion of using development and selection to align managers with strategy. They note that when selecting for fit is a goal, it requires that (a) implementation tasks (i.e., behaviors) be inferred from the strategy, and (b) one can infer managerial skills from those tasks.

Thus, as the previous discussion demonstrates, the Strategic HRM literature has relied extensively on the concept of fit, albeit these treatments of fit have varied quite substantially. In addition, while the exact variables advocated or empirically demonstrated to vary across business strategies have not been exactly the same, these fit relationships seem to involve three generic classes of HR variables: HRM practices, employee skills, and employee behaviors. The consistent themes regarding the variables and processes can be gleaned from this discussion, and these variables form the foundation for our model of Strategic HRM.

\section{A Model of Strategic HRM}

Figure 1 presents a model of Strategic HRM that accounts for both the fit and flexibility goals. The top half of the model depicts the fit component to the model, i.e., the means through which the firm seeks to fit HR practices, employee skills and employee behaviors to the immediate competitive needs of the firm as dictated by the strategy. The lower half of the model illustrates the flexibility component, which focuses on developing the organizational capability to respond to a variety of competitive needs other than those dictated by the current strategy. 


\section{FIGURE 1}

\section{A Model of SHRM}

\section{Formal HR Feedback}

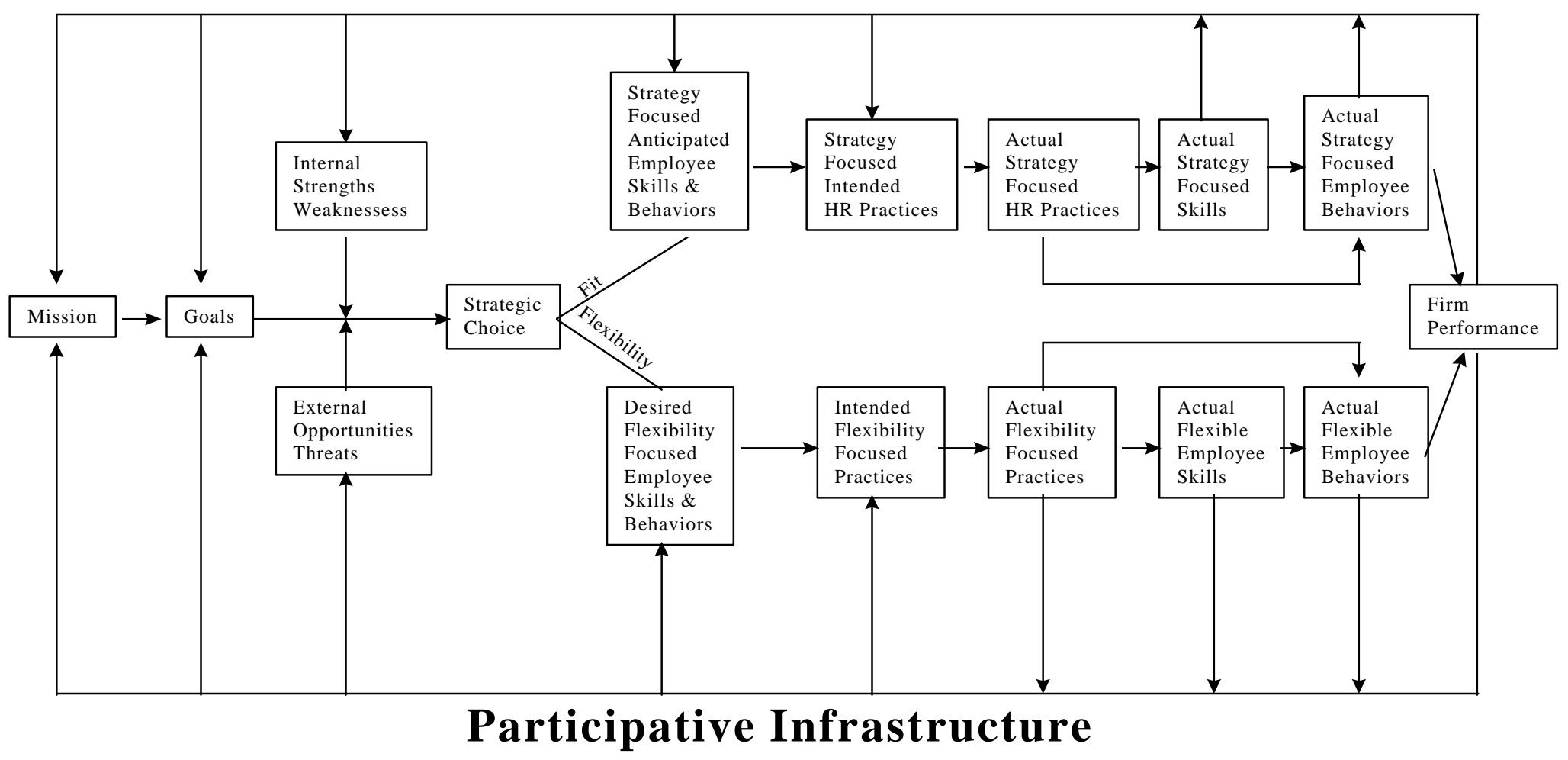




\section{Strategic HRM and Fit}

Numerous authors have presented models of Strategic HRM. For example, Wright and McMahan (1992) presented a basic model proposing that Strategy impacts HR practices, which in turn impact the skills and behaviors of the human resource capital pool resulting in organizational performance. Cappelli and Singh (1992) noted that the basic Strategic HRM assertion that a business strategy should be associated with a unique set of HR practices is based on two unspoken assertions: (1) A particular business strategy requires a unique set of responses from employees and (2) A particular set of HR practices produces a unique set of responses from employees. They note that the validity of the basic strategy - HR practice hypothesis requires that both of the unspoken assertions also be valid. This is somewhat consistent with Schuler and Jackson (1987), who argued that strategy dictates the types of employee role behaviors that are required, resulting in HR practices designed to elicit those role behaviors which impact organizational performance. In addition, the actual role behaviors exhibited are impacted by these HR practices.

An additional component to the model is noted by Truss and Gratton (1994) in their model of Strategic HRM. These authors distinguished between the intended human resource strategy (the HR strategy sought by the firm) and the realized HR interventions (the actual HR practices and systems the firm develops). Consistent with Dyer (1985), they noted that there may be a difference between the articulated HR strategic objectives and the actual practice of HRM within the firm. In fact, this is directly analogous to the distinction between the intended strategy of a firm and the actual realized strategy which reflects the strategy as implemented (Mintzberg, 1994).

The top half of Figure 1 depicts how Strategic HRM promotes organizational fit. At the front end of the model, we propose, consistent with Ansoff (1984), that the strategy formulation process consists of a definition of the mission and goals of the firm, followed by an examination of the internal resources (strengths and weaknesses) and external developments (opportunities and threats). These make up the basic components that lead to the choice of a given strategy. For the sake of the present discussion, we note that this process contains input from the HR function regarding strengths, weaknesses, opportunities and threats related to the firm's human resources, although the extent to which this input exists in most organizations varies substantially (Buller, 1988; Golden \& Ramanujam, 1985; Martell \& Carroll, 1995).

In the model, the major role of HRM is in strategy implementation. The model depicts a process where the firm's strategy dictates the required skills and behaviors as perceived by the top managers or those HR managers who are seeking to implement the strategy (Gupta and 
Govindarajan, 1989; Schuler \& Jackson, 1987; Wright et al., 1995). Thus, it is this perception of the required skills and behaviors that drives the HR practices (Schuler and Jackson, 1987). These HR practices, stem from the perceptions of those involved in implementing the HR strategy regarding which $\mathrm{HR}$ practices will result in developing that skill base in the organization and eliciting the required role behaviors (Snow \& Snell, 1993; Wright et al., 1994). These desired HR practices however, are then operationalized into actual HR practices, and the exact resemblance of the latter to the former is never perfectly assured. The actual HR practices developed influence the actual skills and behaviors of the human resources, thus impacting organizational performance. Finally, organizational performance is fed back into the strategy formulation process, to affect any future strategies.

Note that the preceding model makes some important assumptions with regard to the linkages proposed. First, it assumes that decision makers are able to fully define all of the skills and behaviors that are required of a given strategy and that only these skills and behaviors (as opposed to other skills and behaviors) are related to firm performance. Second, it assumes that the decision makers can fully specify and control all of HR practices within the system. Finally, it assumes that the environment is relatively stable or predictable such that the HR strategy decisions can be made in a way timely enough to ensure that they will achieve a fit with the environment as it exists at the implementation, rather than at the formulation of the strategy. These assumptions form an extremely tightly coupled model of Strategic HRM.

These assumptions are easy to accept in a stable and predictable environment. At the extreme, the firm's evolution may result in the alignment of existing HR practices, skills, and behaviors. Their alignment may endure because it supports the competitive needs of the firm. Thus, fit may exist without any need for flexibility being built into the system.

However, to the extent that environmental stability is replaced by dynamism, achieving fit in Strategic HRM may be desirable but difficult. Furthermore, achieving fit may be dependent upon the extent to which flexibility exists in the system. Accordingly, an HR system may be needed that is sufficiently adaptable to support organizational flexibility. The ways in which flexibility can be built into the Human Resource system of the firm is the topic of the remainder of this paper. The flexibility component of the model is presented briefly below, and the implications of this section of the model are elaborated upon in the following section.

\section{Flexibility in Strategic HRM}

While this role of building flexibility into the firm is increasingly recognized in the Strategic HRM literature (MacDuffie, 1995; Milliman et al., 1991; Snow \& Snell, 1992), this literature is somewhat fragmented without a comprehensive framework for examining the ways 
in which HR can promote organizational flexibility. We propose a framework that focuses on three focal points for flexibility: (1) developing HR systems which are quickly adapted, (2) developing a human capital pool with a broad array of skills, and (3) promoting behavioral flexibility among employees.

The bottom half of Figure 1 depicts the flexibility-based components of our model of Strategic HRM. Note that this component to the model expands upon the fit component in four ways. First, it recognizes that some of the HR practices within the firm are focused on more than just fit. As will be discussed later, HR practices influence the flexibility of employee skills and employee behaviors. Second, this part of the model recognizes of a broader range of skills than those needed to implement the current strategy. Third, it illustrates that the employees possess a broader repertoire of behaviors than just those relevant to the current strategy. These skills and behavioral repertoires represent the capability of employees to implement a variety of different strategies and respond to a variety of different competitive demands in addition to the strategy and demands immediately relevant to the firm. These issues are the focus of the remainder of the paper.

\section{Flexibility and Strategic HRM}

The concept of flexibility has received a good deal of treatment in the strategy literature. We can apply some of that theory directly to HR. Rumelt noted that strategy formulation consists of "the constant search for ways in which the firm's unique resources can be redeployed in changing circumstance," (1984: 569). With regard to developing managers, Kerr and Jackofsky noted that flexibility "....is a function of the range of responses available and the speed with which they can be mounted." (1989: 160). They highlighted the fact that development creates flexibility through creating slack/redundant managerial resources, ensuring the existence of credible champions for new initiatives, and instilling managerial values and attitudes that encourage rapid response. However, in order for organizational flexibility to exist, it must be present throughout the entire organization rather than being confined to a small subset of individuals. This points to the important role that Strategic HRM might play in promoting organizational flexibility.

Sanchez (1995) noted in the context of flexibility in product competition, that there are two basic types of flexibility: Resource flexibility and coordination flexibility. Resource flexibility refers to the extent to which a resource can be applied to a larger range of alternative uses, the costs and difficulty of switching the use of a resource from one alternative use to another, and the time required to switch from one use to another. Coordination flexibility consists of the extent to which the firm can "resynthesize" the strategy, "reconfigure" the chain of resources, 
and "redeploy" the resources. These types of flexibility are particularly applicable for exploring the concept of flexibility in Strategic HRM.

It is interesting to note that while the discussions of fit in Strategic HRM are quite precise in determining the variables that constitute fit, this is not the case regarding flexibility. Milliman et al. (1991) seem to argue for flexibility with regard to HR practices, defining human resource flexibility as "...the capacity of HRM to facilitate the organization's ability to adapt effectively and in a timely manner to changing or diverse demands from either its environment or from within the firm itself," (p. 325).. Snow and Snell (1993) emphasis on creating flexibility through hiring people based on their value creation skills and MacDuffie's (1995) emphasis on flexibility stemming from broad employee skills on the other hand, seem to argue more for flexibility being a product of the skills of the employees. In addition, virtually no one has addressed the idea of flexibility with regard to the behaviors of employees, in spite of the fact that one might assume much of behavior to be more malleable than either skills or HRM practices. Thus, while the concept of fit in Strategic HRM has been well articulated, the concept of flexibility has not.

Thus, within our model, we apply Sanchez's (1995) the concepts of resource and coordination flexibility to HR practices, employee skills and employee behaviors. In essence, flexibility in Strategic HRM can broadly be conceived of as the extent to which the firm's human resources possess skills and behavioral repertoires that can give a firm options for pursuing strategic alternatives in the firm's competitive environment, and the extent to which the necessary HR practices can be quickly identified, developed, and implemented to maximize the flexibilities inherent in those human resources. Note that in our model, HR practices can vary in terms of their own flexibility, and can play an influential role in determining the flexibility or inflexibility of the skills and behaviors of employees. We examine the concepts of resource and coordination flexibility with regard to HR practices, employee skills, and employee behavioral repertoires.

\section{Flexibility and HR Practices}

Flexibility with regard to HR refers to the extent to which practices can differ across locations or business units, the extent to which the basic practices lend themselves to application across different jobs or different sites, and the speed with which practices can be changed. Thus, HR practices can be described in terms of both the resource and coordination flexibility.

HR Practices and Resource Flexibility. The resource flexibility of the HR practices refers to the extent to which they can be adapted and applied across a variety of situations. Two aspects of this flexibility are important. First is the question as to how applicable given HR 
practices are across a variety of situations. Second is the question of the extent to which practices are rigidly applied across situations, even when not applicable.

The first issue deals with the general applicability of an HR practice across jobs and situations in terms of the extent to which the practice must be entirely redesigned or redeveloped to apply to a different situation. An assumption underlying almost all HR practices is that the basic technology for design and development can be applied to create the specific practice for any job. However, the extent of modification necessary to adapt practices developed for one job to another varies considerably. They also may differ considerably in their flexibility in adapting to the unique situations of different individuals in the same job.

For example, a Behavioral Observation Scale (Latham \& Wexley, 1981) used to assess performance is quite narrow in its applicability. It is limited to evaluating employees in one job or job family, and it is assumed that all employees are required to exhibit the same set of behaviors. Management by Objectives (MBO) on the other hand, is an appraisal technique that better resembles a flexible process. While some requirements are standardized (e.g., the need for objective criteria), the application of the technique allows for its use across a larger number of jobs, and for tailoring a set of evaluation criteria for each individual within a given job or job family (Carroll \& Rose, 1973). Similarly, cognitive ability tests have been shown to be applicable across all jobs (Hunter \& Hunter, 1984). In contrast, while work sample tests can be developed for a large variety of jobs, a work sample created for a machinists' job would not be applicable to a clerical position.

The second aspect of resource flexibility of HR practices refers to the extent to which they are rigidly applied across varying situations and sites. Achieving fit between strategy and $\mathrm{HR}$ practices requires that each of the links within the model are perfectly known a priori. To match HR practices to a chosen strategy, the HR strategist has perfect knowledge regarding all of the skills and behaviors required to implement that strategy and the specific HR practices that will develop those skills and elicit those behaviors (Cappelli \& Singh, 1992). In fact, Snell (1992) noted that common views of Strategic HRM embrace "...the rational assumption that managers must have clear knowledge of their organizational contexts, of required behaviors, and of which practices will elicit those behaviors and achieve the firm's strategic goals. Although it may be clear that managers should match preferred human resource management practices to strategy, there is no compelling evidence to suggest that they will, or can, do so." (p. 293).

Even in a single business functioning in a dynamic and uncertain environment, it is highly unlikely that decision makers have anywhere close to perfect knowledge regarding the necessary links posited in the model. Research has consistently demonstrated that individuals 
are poor processors of information, as they misjudge true probabilities, apply inappropriate heuristics, base decisions on biased estimates, and generally fail to understand the true causal set of relationships among variables they encounter (Kahneman, Slovic, \& Tversky, 1982). As has already been discussed, the theoretical and empirical literature regarding these linkages is extremely limited. In particular with regard to HR decision makers, Huselid, Jackson, \& Schuler (1997) found that HR executives were weak in their ability to take their firms' strategic and operational goals and translate them into HR goals and activities.

This problem becomes more apparent with larger, diversified, and geographically disperse organizations. Within firms which possess multiple sites and possibly even multiple diversified businesses, it is important to note that each unit may have unique competitive circumstances which may require a unique system of HR practices. If a centralized HR function attempts to develop a standard set of HR practices to be rigidly applied across all of the sites, then it is likely that many sites will have practices that do not fit well with their unique competitive situation. It is also unlikely that a centralized HR function possesses complete information regarding the business needs of each site to develop an appropriate system of HR practices unique to each site. Consistent with this logic, Teece et al. (1997) argued that decentralization and local autonomy increase flexibility through assisting in the processes of evaluating markets and competitors and reconfiguring and transforming capabilities ahead of competition.

In a recent study of 14 large successful firms, Wright, McMahan, Snell, and Gerhart (1997) found in interviews and surveys of line executives that they often felt the corporate HR function was out of touch with the needs of the business. However, these individuals felt that the HR generalist assigned to their business division was extremely useful in developing systems to deal with the people issues their business faced. This may explain why Huselid (1994), operationalizing internal fit as the extent to which all of the HR practices were similar across divisions found a negative (albeit non-significant) relationship with firm performance. Thus, flexibility with regard to HR practices partially may require some decentralization of authority for the development HR practices in order to allow each operating unit to develop an appropriate system of HR practices for their unique competitive situation.

HR Practices and Coordination Flexibility. The concept of coordination flexibility as applied to HR practices addresses the issue of how quickly the practices can be resynthesized, reconfigured and redeployed. Much of the literature on achieving fit between strategy and HR practices assumes that HR practices are malleable: the HR department 
quickly, efficiently, and effectively develops and implements new practices consistent with a firm's strategic needs in an environment free of obstacles.

However, theorists have noted that, once in place, administrative systems are notoriously intractable (Gerhart \& Milkovich, 1990; Snell \& Dean, 1994). These systems are held in place by numerous forces such as written records, organizational traditions, corporate regulations, and employee expectations. Changes in HR practices result in uncertainty regarding their impact on individuals, and to the extent that the impact can be strong and negative (i.e., risk), individuals will resist the change (Frost \& Egri, 1991). This may be particularly true with regard to practices such as performance appraisal and pay that can significantly change the future outcomes likely to accrue to individuals (Johns, 1993). Thus, any model of flexibility of HR practices must consider the theoretical domain of structural inertia (Astley \& Van de Ven, 1983) and explore the impact of bureaucracy, institutionalization, and political processes on the inertia of HR practices (Wright and McMahan, 1992).

First, as organizations grow and age, they tend toward an increasing bureaucratization which Peterson (1981) termed the "iron law of ossification," (Butler, Ferris, \& Napier, 1991). This ossification can be observed as job descriptions become more rigid and narrow in terms of their activities, objectives, task focus and responsibility. Narrow and rigid job descriptions make it easier to develop selection, appraisal, training, and compensation systems which become tightly coupled together. This substantially reduces the ability to change any one of the HR practices. This ossification negatively impacts the organization's ability to act in response to changes in the environment.

Second, institutional theory posits that organizational practices such as human resource practices develop and attain legitimacy through the social construction of reality (Oliver, 1997). According to Meyer and Rowan "Institutionalism involves the processes by which social processes, obligations, or actualities come to take on a rulelike status in social thought and actions," (1977: 341). Scott stated that this process culminates in a situation where individuals come to accept shared definitions of reality or "...conceptions whose validity is seen as independent of the actor's own views or actions but is taken for granted as defining the 'way things are' and/or the 'way things are to be done,'" (1987: 496). To the extent that these shared definitions of what comprises legitimate HR practices exists within a firm, the likelihood of significant changes in those practices is reduced.

Finally, political processes often work to inhibit unobstructed change in HR practices (Oliver, 1997). HR practices often come about not from functional or technological requirements, but from organizational processes such as power and influence, conflict, and 
contests for control (Cohen \& Pfeffer, 1984; Johns, 1993). Assuming that the status quo among a firm's HR practices reflects at least in part the outcome of these political process, changes in HR practices require battling the internal power structure. This, in part explains why Wolfe (1995) noted that one determinant of the successful implementation of HR innovations was a powerful champion of the innovation. Thus, the bureaucratic, institutional, and political processes strongly impact the flexibility of the HR practices. Consequently, these limit the coordination flexibility inherent in the firm (Oliver, 1997).

An additional determinant of a firm's coordination flexibility in HR practices is speed with which feedback about the efficacy of an implemented HR system can be obtained. Most treatments of the Strategic HRM process assumes that the entire process takes place almost simultaneously, or at least with such a short temporal lag that feedback regarding the efficacy of new HR systems can be obtained quickly. This enables a firm to track the effectiveness of the HR practices and to make timely adjustments. This assumption is even more suspicious when considering the feedback loop within the model.

For example, consider the situation where a formal strategy is put forth which entails a major change in direction relative to the business's past strategic intention, and consequently a major overhaul in the skills and behaviors of the firm's human resources with a corresponding change in HR practices. The issue of speed of implementation of HR practices has already been discussed. Then, due to the slow flow of employees through the system as old employees with the obsolete skills leave and the new employees with desired skills are selected in (Boudreau \& Rynes, 1985), the effects of some of these systems may take 2-3 more years before they provide the anticipated impact.

This process is further complicated by the feedback loop. Given the failure to completely implement the HR strategy at this point, feedback at the end of year 1 might have nothing to do with its efficacy. Even feedback in years 2 and 3 might be misleading given the fact that the effects of the HR strategy should not be pronounced. By the time that the feedback regarding the efficacy of the HR strategy might be valid (e.g., year 4 or 5), the entire system environment (external environment as well as firm strategy) may have changed such that the feedback is now regarding a system no longer in existence. Thus, one goal for developing flexibility in HR practices is to develop feedback systems which provide accurate and timely information regarding the efficacy of a particular practice or system of practices.

Summary. This discussion illustrates the importance of creating flexibility of HR practices. While at first glance the description of the factors that impede change in HR practices might lead one to believe that achieving fit is impossible, this is not the case. Clearly, variance 
exists with regard to knowledge of causal links and controllability across a variety of HR practices. For instance, firms seeking total quality can envision and implement incentive systems that tie individual and group rewards to total quality outcomes as well as training programs necessary to provide individuals and groups with the skills necessary to achieve those outcomes. However, HR practices as well as employees skills and behavior necessary for implementing more generic strategies such as innovation or differentiation might be less clear.

Similarly, just as certain strategy - HR practice links are clearer than others, certain HR practices are more amenable to timely changes than others. For example, while the move from a purely fixed pay system (e.g., salary) to a more heavily variable pay-oriented system (e.g., bonuses, gain sharing, profit sharing) may require significant study and negotiation, changes in the actual pay performance ties (e.g., changing bonuses from being tied to growth to being tied to profitability) may be more easily achieved. In addition, certain HR practices (e.g., compensation) will have a more immediate impact on employee behavior than others (e.g., selection).

In addition, the system feedback speed varies. Some changes HR practices can be quickly implemented and with almost immediate feedback. For example, the impact of the implementation of a bonus/incentive system might be almost immediate (Wright, 1994). However, the impact of a selection or training program might be longer. In fact, Carnazza (1982) estimated that a management development program can take 5 years to mature, and that even then, it may not yet have resulted in a tangible positive return on investment.

Thus, HR practices can vary in terms of the practices' ability to be effectively applied across a variety of different situations, the variability in practices allowed across locations, the ease/quickness in implementing appropriate practices, and the speed with which feedback is obtained regarding the utility of the system of practices. All of these indicators of flexibility of HR practices serve as indicators of the flexibility of the firm. To the extent that the HR practices are flexible (in terms of both resource and coordination flexibility), the firm's overall flexibility is increased. In addition, HR practices themselves can influence the flexibility of employee skills and behaviors. This will be discussed below.

\section{Employee Skills and Flexibility}

As discussed previously, most researchers who have explored the role of HR in promoting firm flexibility have focused on the ranges and types of employee skills resulting from the application of HR practices. Similar to the analysis with regard to HR practices, both the concepts of resource and coordination flexibility are relevant to workforce skills. 
Employee Skills and Resource Flexibility. Resource flexibility in employee skills refers to the number of potential alternative uses to which the skills can be applied. One aspect of resource flexibility refers to the potential uses to which each employee can be applied. Employees who possess broad sets of skills enabling them to accomplish a large number of diverse tasks provide operational resource flexibility on a day-to-day basis (Dean \& Snell, 1994; MacDuffie, 1995). Skill-based pay plans, for example, provide one way of encouraging the development of such broad skills (Ledford, 1995).

In addition, resource flexibility might be developed in a longer term fashion. The speed with which individuals learn to perform new tasks is becoming increasingly important in today's environment of rapid technological change as well as the new psychological contract that offers "employability" through developmental experiences (Guion, 1997; Ehrlich, 1994). Thus, rather than focusing on the immediate breadth of skills, it is also important to develop flexibility through ensuring that employees possess the foundational skills that will enable them to develop broader skills in the future. For example, Snow and Snell's (1993) call for a Model 3 selection strategy that focuses on selecting individuals for their value creation skills such as cognitive ability rather than a narrow skill fit with an existing set of job requirements exemplifies an orientation toward achieving resource flexibility.

Netscape's recruiting of programmers exemplifies this approach to developing flexibility in skills. In order to meet their immediate programming needs, they must focus on recruiting programmers who are currently proficient in the hottest language (such as Java). However, the value of these programmers as long-term employees will depend more upon their ability to adapt quickly to the next language. Thus, Boudreau and Ramsted suggest that "...mental abilities, flexible behaviors, and even personality traits associated with adaptability to change," might better reflect the value of these employees to the firm (1997: 352).

Employee Skills and Coordination Flexibility. Coordination flexibility with regard to employee skills refers to how individuals with different skills can be quickly redeployed in the value chain. In this vein, firms can seek a wide range of skills through selecting a large number of individuals possessing a very narrow range of skills and then deploying and redeploying them wherever their skills are needed. For example, Miles and Snow's (1978) categorization of an Analyzer strategy referred to a firm competing in a variety of product markets. The task for these firms was one of quickly and efficiently shifting existing resources from one market to another in response to changes in the markets. In other words, if one market suddenly absolutely required some narrow skill set, the firm might be able to shift an existing employee or group possessing those skills from one market to the other market which required those skills. 
This is exemplified by AT\&T's Resource Link, which provides a data base of employee skills. Thus, whenever an individual with a certain skill set is required within one division of AT\&T, the hiring manager can access the database to identify potential hires in other divisions.

Increasingly, coordination flexibility of skills is being achieved by the use of contingent workers. Firms are able to hire individuals with a narrow set of skills to complete a specified project. Then when the project is over or the product is being replaced, these contingent workers are released and a new set of contingent workers can be brought in whose narrow skill set meets the needs of a new project (Kochan, Smith, Wells, and Rebitzer, 1994).

Summary. The breadth of skills available to the firm provides an indication of the potential flexibility of the firm. This flexibility consists of both resource and coordination flexibility. While the breadth of the skills available determines the firm's flexibility, it is important to note that at any point in time, this might only represent the potential, rather than realized flexibility. In other words, the firm's current strategic needs might specify a narrow range of skills. However, to the extent that the firm possesses a broader range of skills that might not currently be exploited, those skills provide the firm with the potential capability to implement alternative strategies (i.e., functional slack). Thus, to the extent that the workforce possesses a variety of skills (both resource and coordination flexibility), the firm's overall resource flexibility increases.

\section{Behavioral Repertoires and Flexibility}

Finally, the flexibility that exists with regard to employee behavior also determines the flexibility of a firm. The importance of employee behavior is most recently noted by MacDuffie who stated that "Skilled and knowledgeable workers who are not motivated are unlikely to contribute any discretionary effort. Motivated workers who lack skills or knowledge may contribute discretionary effort with little impact on performance," (1995: 199). He noted that motivation to exhibit discretionary effort stems in large part from employees believing that their individual interests are aligned with those of the firm. Similarly, Boxall (forthcoming) distinguished between the "can-do" goal of Strategic HRM (developing workforce skills) and the "will-do" goal (eliciting motivation and commitment to align employee behavior to the interests of the firm).

Organizational flexibility comes to life through employees exhibiting appropriate behavioral scripts to given situations. These behavioral scripts consist of sequences of behavioral events expected by an individual. They are similar to what others have called routines (Berger \& Luckman, 1966). They are dependent on an individual's history of experiences both as a participant in event sequences and as an observer (Abelson, 1976). A 
script is stored as a sequential unit of understanding and is called upon at appropriate moments during human functioning. Individuals possess scripts for situations that they have encountered and these scripts provide shared meanings and behaviors which facilitate the coordination of activities within a social system (March and Simon, 1958). Cognitively mediated social behaviors depend on the dual occurrences of (1) the selection of a particular script to represent the given situation, and (2) the individual assuming a participant role within that script (Abelson, 1976).

Flexibility of organizations stems from the availability of a vast repertoire of behavioral scripts among employees. Flexibility is necessary so that existing practices can be altered in response to nontransient changes in the environment (Weick, 1979). The firm must possess a sufficient repertoire of novel scripts among organizational members that allows them to recognize and accommodate these ecological changes. Weick refers to this as a two choice process. The "interpretation choice" consists of asking the question "Knowing what I know now, should I change the way I label and connect the flow of experience?" in order to determine if an individual should revise the interpretation of a given situation. The second choice is the "enactment choice" where individuals ask the questions "Knowing what I know now, should I act differently?" in order to determine if one should revise the behavioral responses that create or respond to change.

Behavioral Scripts and Resource Flexibility. Behavioral scripts have relevance to both resource and coordination flexibility. These behavioral scripts are extremely relevant to resource flexibility because a script becomes stronger as the frequency of calling on the script increases (Schank \& Abelson, 1977). Thus, as employees engage in repetitive handling of situations through the application of a particular script, they increase the likelihood that the script will be selected to represent a particular situation. To the extent that the probability of selecting a particular script increases, the repertoire of potential behavioral scripts is reduced. In essence, the same processes referred to as bureaucratization and institutionalization of HR practices can take place with regard to individual's behavioral scripts. The script becomes institutionalized, thus, losing its novelty and becoming part of the objective reality of the firm (Zucker, 1977).

HR practices can strongly influence, positively or negatively, the behavioral resource flexibility that exists in a firm. Very specific behavioral appraisal systems such as BOS (Latham \& Wexley, 1981), narrow job descriptions, and rigid standard operating procedures should decrease behavioral flexibility. On the other hand, developmental experiences or assignments are usually aimed at increasing the behavioral repertoires available to managers. Through 
working in departments or businesses that are unlike their own, managers can face different problems with different solutions, and thus, increase their capacity to recognize a greater variety of contingencies and to have a greater set of behavioral responses at their disposal (Noe, Wilk, Mullen, \& Wanek, 1997).

The importance the resource flexibility component of behavioral scripts is illustrated by comparing Southwest Airline's ways of managing the workforce to those of other airlines. Most of the major firms in the U.S. airline industry have developed very specific job descriptions and work rules to control employee behavior. Southwest, on the other hand, eschews such techniques. Instead management emphasizes the importance of both getting planes out on time and doing what is in the best interest of the company, then provides employees with great latitude in deciding how to accomplish those goals (Freiberg \& Freiberg, 1997). Says Herb Kelleher, CEO, "We tell our people that we value inconsistency. By that I mean that we're going to carry 20 million passengers this year and that I can't foresee all of the situations that will arise at the stations across our system. So what we tell our people is, 'Hey, we can't anticipate all of these things, you handle them the best way possible. You make a judgment and use your discretion; we trust you'll do the right thing. If we think you've done something erroneous, we'll let you know--without criticism, without backbiting."' (Quick, 1992).

Behavioral Scripts and Coordination Flexibility. In addition, the coordination flexibility concept is relevant to behavioral scripts. As behavioral scripts become more homogeneous, it reduces the diversity of perspectives and thus reducing the potential for conflict. Because members share the same scripts regarding appropriate responses to similarly perceived situations, these scripts also serve as coordinating mechanisms. However, these positive benefits of increased coordination and reduced conflict might be more than offset by the negative side effects of reduced diversity of points of view.

Ginsberg's (1993) discussion of the need for heterogeneity among top managers illustrates the efficacy of having diverse viewpoints. Individuals with different scripts bring different interpretation choices and enactment choices (Weick, 1979). However, diverse viewpoints create coordination and conflict problems. This highlights the need for coordination flexibility that enables the firm to synthesize and deploy the different perspectives in a way that maximized decision effectiveness.

Continental Airlines' recent turnaround, particularly with regard to their on-timeperformance exemplifies the importance of coordination flexibility with regard to behavioral scripts as well as the impact of HR practices on those scripts. Prior to Continental's turnaround, one problem within the airline was that functions were compartmentalized with competing goals. 
For example, the field services crew was expected to close the cabin door within 3 minutes of departure time, while the In-flight crew was supposed to focus on customers comfort even if it meant waiting for delivery of extra service items such as blankets or pillows. Thus, each group possessed crystalized and contradictory behavioral scripts which resulted in a situation where one group was trying to close the door and the other trying to hold it open (Carrig, 1997). To eliminate this problem, Continental instituted an on-time bonus, where every employee received a $\$ 65$ check for every month that the company placed in the top 3 in the industry in on-time performance. The result was that by the second month the bonus was in effect, Continental rose from $10^{\text {th }}$ to $1^{\text {st }}$ in the industry (Flynn, 1997). Note that this change in performance stemmed not from a change in skills, as the workforce was the same group of individuals. Rather, the change in performance stemmed from eliminating the old behavioral scripts which called for doing what was best for a particular group, and developing behavioral scripts around achieving a common goal.

Summary. Thus, the flexibility of employee behavior provides an indicator of the firm's flexibility. Employees who possess a variety of behavioral scripts and are encouraged to apply them in appropriate situations rather than follow standard operating procedures increase the likelihood of the firm identifying new competitive situations and responding appropriately. Similarly, flexibility is achieved through the coordination of behavioral scripts across individuals and groups.

It is important to note that distinguishing between skills and behaviors does not require that they be independent. In fact, in most cases skills form the foundation for the array of potential behaviors an individual can display. However, consistent with what MacDuffie (1995) referred to as "discretionary" behavior, the importance of the distinction lies in recognizing that their foundational skills usually allow employees a plethora of alternative behaviors to exhibit. However, over time, institutional processes described earlier may cause certain behavioral scripts to take on a rule-like status, resulting in employees failing to make correct choices with regard to both interpretation and enactment of a given situation. This inflexibility can impede the exhibition of behaviors which might benefit the long term performance of the firm, but run counter to the standard operating procedure. Thus, the key to attaining behavioral flexibility is in enlarging and eliciting the range of discretionary behaviors which result in positive organizational outcomes.

Thus, the repertoire of behaviors scripts comprise an important component of the firm's flexibility. To the extent that employees possess a wide variety of behavioral scripts (resource 
flexibility) and systems exist to synthesize these scripts (coordination flexibility), the firm's flexibility is increased.

\section{Implications for Strategic HRM Practice}

This analysis highlights another way in which Strategic HRM can contribute to a firm's competitive advantage. Strategic HRM can play an integral role in determining the organization's flexibility. Table 1 summarizes these aspects of firm flexibility that are influenced by Strategic HRM.

\section{Table 1.}

\section{Strategic HRM Indicators of Resource and Coordination Flexibility}

Strategic HRM Component Resource Flexibility

Practices

Rigidity of Application
Across jobs, etc.

Employee Skills

$\begin{array}{ll} & \begin{array}{c}\text { Ability to Acquire } \\ \text { Skills }\end{array} \\ \text { Employee Behavior } & \begin{array}{l}\text { Rigidity of Script } \\ \text { Application }\end{array}\end{array}$

Across jobs, etc.
Coordination Flexibility

Malleability of Practices

Applicability of Practices

Individual Skill Breadth

Speed of Feedback on Practice Impact

Variety of skills in the Workforce

Ability to Acquire diverse Skills from Contingent Workers

Complementarity/Conflict Between scripts of Different groups

To the extent that bureaucracy and inertia can be minimized, HR practices can be quickly changed to meet the needs of a changing environment. To the extent that the workforce possesses a variety of skills and behavioral repertoires, the firm's flexibility is increased. Thus, the key role of Strategic HRM is to seek to ensure fit among a subset of strategically relevant variables while simultaneously seeking to build generic organizational capabilities that can be applied toward both discovering and implementing a variety of diverse strategic initiatives. In this section we will examine the implications of this discussion for Strategic HRM practice in terms of the role of HRM practices and the role of HR in strategy formulation and competitive advantage. 


\section{Fit, Flexibility, and HRM Practices}

Not surprisingly, we argue that theoretically, Strategic HRM in practice may consist of developing systems of HRM practices that simultaneously promote both fit and flexibility. The system aspect of HRM is important because it highlights the fact that multiple HRM practices exist within a firm. Thus, while one HRM practice (e.g., a particular selection test) might only be able to promote fit or flexibility, additional practices exist that can promote the other goal. Thus, the simultaneous pursuit of both fit and flexibility is achieved through focusing certain aspects of the HRM system on achieving fit while focusing others on achieving flexibility. Because and HRM systems consists of a menu or set of different HRM practices, some aspects of the system can promote fit while others can promote flexibility.

With regard to achieving fit in Strategic HRM, we recognize the importance of developing and applying HRM practices aimed at achieving fit. For example, firms that seek to increase levels of customer service can develop selection tests such as role plays or interviews that assess an individual's skill in providing customer service. Training programs can be developed to increase these skills. In addition, appraisal and incentive systems can be aimed at assessing and rewarding customer service behavior. However, consistent with Milliman et al. (1991), we would note that fit is a short term goal, particulary with regard to more day-to-day operationalization of strategy.

Our model suggests that fit is probably most easily achieved by focusing HR practices such as appraisal, rewards, and communications on eliciting the behaviors most relevant to the strategy. This, of course requires that individuals possess the skills necessary to exhibit those behaviors (Wright, et al., 1994). However, for many existing organizations, the skills necessary to exhibit the behaviors exist, but they are not being utilized because the reward system rewards other behaviors.

In addition, HR practices can also simultaneously promote flexibility within the firm. Certain intractable or institutionalized HR practices might still promote firm flexibility through the development of wide ranges of employee skills and behavioral repertoires. The skills and behavioral repertoires held by employees in large part result from the application of certain HR practices (Wright, McMahan, \& McWilliams, 1994). Innovative selection systems which seek to identify individuals with the ability to learn and adapt to new situations can provide a firm with competitive advantage (Snow \& Snell, 1993). Training programs increase the skills and behavioral repertoires of employees in a way that can impact both efficiency (Cooke, 1994) and adaptability. Developmental experiences such as job rotation and temporary assignments focus on broadening both the skills and behavioral repertoires of individuals. Similarly, appraisal and 
compensation systems can motivate skilled employees to engage in effective discretionary decision making and behavior in response to a variety of environmental contingencies (MacDuffie, 1995). Finally, recent research indicates that these HR practices provide maximal effectiveness when bundled with participative work systems that provide employees with the opportunities to contribute their discretionary behavior toward the achievement of organizational goals (MacDuffie, 1995; Wright, McCormick, Sherman, \& McMahan, 1995).

\section{Fit, Flexibility, and Strategy Formulation}

Finally, our discussion of fit and flexibility has implications for a more active role for Strategic HRM in strategy formulation. The roles differ depending upon whether the focus is on fit or on flexibility. These roles will be discussed.

Golden and Ramanujam (1985) identified four levels of integration between the HR and strategic planning functions. Of these four, only two consisted of any role for HR in strategy formulation. However, their research as well as more recent work by Buller (1988) has found that few firms exhibit the integrative level of linkage where the HR executive is a member of the top management team. Most recently, Martell \& Carroll (1996), in a study of 115 SBU's of Fortune 500 companies, found that HRM and the strategic planning process was linked in between $44 \%$ and $69 \%$ of the firms. However, they found that the HR function was viewed as less important than other functions.

Mintzberg (1994) distinguished strategic planning "strategic programming" which takes a perspective of breaking down a goal into a set of action steps, formalizing those steps for automatic implementation and articulating the results of these steps, from "strategic thinking" which entails taking information from numerous sources and integrating that information into a vision of what direction the business should pursue. Strategic programming seems quite consistent with an emphasis on achieving fit and the two-way linkage described by Golden and Ramanujam (1984), whereas the strategic thinking is consistent with an emphasis on building flexibility and the integrative linkage. This distinction highlights the dual roles of HR in strategic management and the different requirements of each.

Achieving fit requires an important role for the HR function in strategy formulation. The goal is to achieve fit among strategy and HR practices, employee skills, and employee behaviors. A simplistic (and popular) view of this is that strategy is considered a given, and the rest of the HR system is assumed to respond to implement the strategy. However, Cappelli and Singh (1992) pointed out that substantial evidence exists noting the difficulties of organizational change (including HR practices, employee skills and employee behavior). 
Thus, if fit is the goal, it may be that it is considerably easier to fit the strategy to the skills that the firm possesses, than to fit the skills to the strategy desired (Wright et al., 1995.) If so, then HR's role consists of monitoring the actual HR skills and behaviors of the firm as they relate to firm performance, and feeding this information back into the strategy formulation process to influence the firm's strategic choice (Wright et al., 1994). In other words, HR provides information which will negate choosing certain strategies with which the HR system is not congruent. Thus, in achieving fit, HR should play an important role in strategy formulation, but this role is a limiting one. Note that this is the process depicted in the top half of Figure 1.

On the other hand, the flexibility component of the model expands the role of HR in strategy formulation even further. HR can promote the development of a workforce with the broad base of skills and behavioral repertoires necessary to respond to a variety of demands, i.e., implement a variety of different strategies. In fact, this increases the probability that alternative strategies will be generated within the firm outside of the formal strategic planning process.

It also entails the development of a participative infrastructure that enables the firm to better monitor and respond to changes in the competitive environment. This illustrates the indirect influence that the HR function can have on strategy formulation by creating the participative infrastructure through which the firm's human resources can impact organizational strategy. The participative infrastructure refers to the mechanisms the firm uses to provide maximum amounts of information to employees, to decentralize decision making, and to encourage employees to provide information or input into the firm's decision making processes (MacDuffie, 1995; Cooke, 1994).

It is this participative infrastructure that enables employees to recognize and respond to such things as customer needs and competitor actions, and to communicate those needs and responses throughout the firm. This information forms the foundation for input regarding external opportunities and threats as well as internal strengths and weaknesses. This information is disseminated and linked with similar information, providing decision makers with the most up-to-date and accurate information regarding changing environmental contingencies. In fact, Wright, McCormick, Sherman, \& McMahan (1995) and MacDuffie (1995) both found support for the idea the HR practices are most effective when paired with a participative infrastructure. The participative infrastructure increases the ability of managers to find "...those fledgling strategies in their organizations or those of competing organizations." (Mintzberg, 1994: 113). This is depicted in the bottom half of Figure 1. 


\section{Fit, Flexibility, and Competitive Advantage}

The previous discussion noted that seeking fit requires (1) knowledge of the skills and behaviors necessary to implement the strategy, (2) knowledge of the HR practices necessary to elicit those skills and behaviors, and (3) the ability to quickly implement the desired system of HR practices. These assumptions of the fit model point to the difficulty of achieving fit. However, this difficulty, in fact, leads to one way in which firms can gain competitive advantage.

Barney (1991) noted that sustainable competitive advantage stems from resources or capabilities which are valuable, rare, difficult to imitate and non-substitutable. Because achieving fit is difficult regardless of the dynamism of the environment, firms which are able to do so possess a resource which meets Barneys' criteria for competitive advantage. In addition, particularly in firms facing dynamic competitive environments, developing the ability to flexibly achieve fit with constantly changing strategic needs provides an even greater strategic asset. This kind of capability is at least one component of the dynamic capabilities discussed by Teece et al. (1997).

This leads to linking recent research on the necessary competencies for HR executives in today's firms. Ulrich and Lake (1990) note that knowledge of business, delivery of HR, management of change, and personal credibility. Personal credibility aside, note how these competencies track with the requirements for achieving fit. Without knowledge of the business, HR executives would be ill-equipped to define the kinds of skills and behaviors necessary to implement the business strategy. Without knowledge of the delivery of HR, they would find it impossible to identify HR practices which could elicit these skills and behaviors. And without the competence in managing change, they would be unable to quickly and effectively implement these desired HR practices. Our experience is that HR executives who possess all of these competencies are in short supply, and thus, may also provide a source of competitive advantage.

\section{Implications for Strategic HRM Research}

Recognizing the dual roles of Strategic HRM in achieving both fit and flexibility has implications for expanding the types of research questions that will further our knowledge of the role of HR in firm performance. First, the distinctions between focusing on fit or flexibility in HR practices, skills, and/or behaviors provides a more well specified framework for future research. It points to the need for research distinguishing among HR practices, skills, and behaviors that are tightly coupled with the short term strategic needs of the firm versus those that are loosely coupled. For example, some firms may emphasize coupling the strategy to skills (via changes in recruiting and selection systems), others may tightly couple strategy and behaviors (via 
changes in appraisal and reward systems), while others may couple strategy with both and others with neither.

In addition, our model also points to the need for research to examine how firms achieve simultaneous loose/tight coupling through focusing on fit in some aspects of the HR system while emphasizing flexibility in other aspects. Clearly, certain strategic needs require tight coupling with only a specific set of HR practices, skills and behaviors. For example, a firm that focuses on an increased level of customer service may include some aspect of assessing applicants' customer orientation in the selection process, but might still seek to assess other skills (intelligence, conscientiousness, etc.). In addition, this emphasis may require altering aspects of the appraisal and compensation systems to assess and reward customer service behavior, while other aspects of the systems remain the same.

Third, our model provides an impetus for examining the timing of strategic HR decision making and implementation. As noted with regard to the fit based model, most treatments of Strategic HRM decision implicitly assume that firm strategies, HR strategies, HR practices, and the skills and behaviors emanating from those practices occur within a very limited time frame. However recognizing the lack of information and institutional and poltical processes previously discussed points to a need for better data on the time frame involved in the Strategic HRM process. How long do most Strategic HRM decisions take from problem/issue definition to decision? How much time typically elapses between the decision until the implementation of actual HR practices, policies, or programs? Once these practices, policies or programs are implemented, how long does it take until their impact is evident in the skills and/or behaviors of the target workforce? Finally, how long does it take from the manifestation of skills and/or behaviors until their impact is observed?

Research also must distinguish among the various aspects of the model with regard to the timing issue. The above questions focus on understanding average timing across all issues, practices, skills, and behaviors. However, variance exists in how quickly certain strategic issues can be processed and decisions reached, how quickly certain HR practices can be implemented, how quickly certain skills and/or behaviors can be elicited, and how quickly the impact of certain aforementioned changes can be observed. Thus, future research could focus on identifying the types of strategic HR issues, HR practices, skills and behaviors that are amenable to almost immediate decision making, implementation, and impact, as opposed to those that require greater time frames. Such an exploration can move us beyond overly simplistic models of Strategic HRM toward a much richer understanding of the role of Strategic HRM in organizations. 


\section{Conclusion}

Given the increasing importance of Strategic HRM for creating firm competitive advantage, much more theoretical development is necessary in the field (Wright \& McMahan, 1992). This paper has focused on more specifically delineating the treatments of fit and flexibility in the Strategic HRM literature. We have demonstrated that these treatments are not necessarily consistent and have provided an overall integrating framework through focusing on HRM practices, HR skills, and HR behaviors. In addition, we have used this model to identified some of the factors that influence the flexibility of a firm which enables it to achieve fit in a dynamic competitive environment. We have noted the fuzzy treatment of the concept of flexibility in Strategic HRM research, and have attempted to provide a more specific framework for future examinations. Finally, we have explored the implications for our models on both practice and research in Strategic HRM.

Absent a unifying framework of the Strategic HRM process, theoretical development in the literature will be limited (Wright \& McMahan, 1992). It is our hope that the framework and model presented here provides at least a starting point for future explorations of the concepts of fit and flexibility as they apply to the research and practice of Strategic HRM in organizations. 


\section{References}

Abelson, R.P. 1976. Script processing in attitude formation and decision-making. In J. Carroll \& J. Payne, (Eds.), Cognition and Social Behavior 33-45. Hillsdale, NJ: Lawrence Erlbaum.

Ansoff, H. (1984). Implanting Strategic Management, Englewood Cliffs, NJ: Prentice-Hall.

Arthur, J.B. 1992. The link between business strategy and industrial relations systems in American steel minimills. Industrial and Labor Relations Review, 45(3): 488-506.

Arthur, J.B. 1994. Effects of human resource systems on manufacturing performance and turnover. Academy of Management Journal, 37: 670-687.

Astley, W. \& Van de Ven, A. 1983. Central perspectives and debates in organization theory. Administrative Science Quarterly, 28: 245-273.

Baird, L. \& Meshoulam, I. 1988. Managing two fits of strategic human resource management. Academy of Management Review, 13(1): 116-128.

Balkin, D.B. \& Gomez-Mejia, L.R. 1987. Toward a contingency theory of compensation strategy. Strategic Management Journal, 8: 169-182.

Balkin, D.B., \& Gomez-Mejia, L.R. 1990. Matching compensation and organizational strategies. Strategic Management Journal, 11: 153-169.

Bantel, K. \& Jackson, S. 1989. Top management and innovations in banking: Does the composition of the top team make a difference? Strategic Management Journal, 10: 107-124.

Barney, J. (1991). Firm Resources and Sustained Competitive Advantage. Journal of Management, 17, 99-120.

Becker, B., \& Gerhart, B. 1996. The impact of human resource management on organizational performance: Progress and prospects. Academy of Management Journal 39: 779-801.

Bennett, N. \& Schultz, E. 1995. Is anyone listening? An empirical test of prescribed relations between human resource management and strategic type. Paper presented at 1995 Academy of Management meeting, Vancouver, BC.

Berger, P. \& Luckman, T. 1966. The social construction of reality: A treatise in the sociology of knowledge. Garden City, NJ: Doubleday.

Boudreau, J. \& Rynes, S. 1985. Role of recruitment in staffing utility analysis. Journal of Applied Psychology, 70: 354-366.

Boudreau, J. \& Ramsted, P. 1997. Measuring intellectual capital: Learning from financial history. Human Resource Management, 36(3): 343-356. 
Boxall, P. Forthcoming. Human resource strategy and industry-based competition: A framework for analysis and action. In G. Ferris (ed.), Research in Personnel and Human Resource Management .

Buller, P. 1988. Successful partnerships: HR and strategic planning at eight top firms. Organizational Dynamics, 17: 27-42.

Butler, J.E., Ferris, G.R. \& Napier, N.K. 1991. Chap. 2, 9-59, Human resources management: Moving towards a paradigm and obtaining advantage. Strategy and Human Resource Management, Cincinnati, $\mathrm{OH}$ : South-Western Publishing Company.

Cappelli, P. \& Singh, H. 1992. Integrating strategic human resources and strategic management. In D. Lewin, O.S. Mitchell \& P. Sherer (Eds.), Research frontiers in industrial relations and human resources, Madison, WI: Industrial Relations Research Association.

Carnazza, J. 1982. Succession/replacement planning: Programs and practices. Center for Research in Career Development, Columbia University.

Carrig, K. 1997. From worst to first: Continental Airlines and the changing role of human resources. Unpublished manuscript.

Carroll, S., \& Rose, H. 1973. Management by Objectives: Applications and Research. New York, NY: MacMillan.

Chakravarthy, B.S. 1982. Adaptation: A promising metaphor for strtegic management. Academy of Management Review, 7: 35-44.

Cohen, Y. \& Pfeffer, J. 1986. Organizational hiring standards. Administrative Science Quarterly, 31: 1-24.

Cooke, W. 1994. Employee participation programs, group-based incentives, and company performance: A union-nonunion comparison. Industrial and Labor Relations Review, 47: 594-609.

Delery, J.E. \& Doty, D.H. 1996. Theoretical frameworks in strategic human resource management: Universalistic, contingency, and configurational perspectives. Academy of Management Journal, 39: 802-835.

Dyer, L. 1985. Strategic human resource management and planning. In K. Rowland \& G. Ferris (Eds.), Research in Personnel and human resources management 3: 1-30. Greenwich, CT: JAI Press.

Ehrlich, C. 1994. Creating an Employer-Employee Relationship for the future. Human Resource Management, 33(3): 491-502.

Flynn, G. (1997). A flight plan for success. Workforce, July, 72-78.

Freiberg, K, \& Freiberg, J. (1997). Nuts! Southwest Airlines Crazy Recipe for Busines and Personal Success. Austin, TX: Bard Press. 
Frost, P. \& Egri, C. 1991. The political process of innovation. In B. Staue \& L. Cummings (eds.) Research in Organizational Behavior, 13: 229-296.

Gerhart, B. \& Milkovich, G.T. 1990. Organizational differences in managerial compensation and financial performance. Academy of Management Journal, 33: 663-691.

Gerhart, B., Trevor, C., \& Graham, M. (1996). New Directions in Employee Compensation Research. In G.R., Ferris (Ed.), Research in Personnel and Human Resource Management. Vol. 14, 143-204.

Gerstein, M., \& Reisman, H. 1983. Strategic selection: Matching executives to business conditions. Sloan Management Review, 24:(2): 33-49.

Ginsberg, A. 1994. Minding the competition: From mapping to mastery. Strategic Management Journal, 15: 153-174.

Golden, K. \& Ramanujam, V. 1985. Between a dream and a nightmare: On the integration of the human resource management and strategic business planning processes. Human Resource Management, 24: 429-452.

Gomez-Mejia, L.R. 1992. Structure and process of diversification, compensation strategy, and firm performance. Strategic Management Journal, 13: 381-397.

Guion, R. 1997. Criterion measures and the criterion dilemma. In Neil Anderson and Peer Herriot (Eds.) International Handbook of Selection and Assessment, John Wiley and Sons.

Gupta, A. 1984. Contingency linkages between strategy and general managers characteristics: a conceptual examination. Academy of Management Review, 9: 399-412.

Gupta, A.K. \& Govindarajan, V. 1984. Business unit strategy, managerial characteristics, and business unit effectiveness at strategy implementation. Academy of Management Journal, 27: 25-41.

Hambrick, D., \& Mason, P. 1984. Upper echelons: The organization as a reflection of its top managers. Academy of Management Review, 9: 193-206.

Hamel, G. \& Prahalad, C.K. 1994. Competing for the Future. Cambridge, MA: Harvard Business School Press.

Hansen, G.S. \& Wernerfelt, B. 1989. Determinants of firm performance: The relative importance of economic and organizational factors. Strategic Management Journal, 10: 399-411.

Hitt, M. \& Tyler, B. 1992. Strategic decision models: Integrating different perspectives. Strategic Management Journal, 12: 327-351.

Hunter, J., \& Hunter, R. 1984. Validity and Utility of alternative predictors of job performance. Psychological Bulletin, 96(1): 72-98. 
Huselid, M.A. 1995. The impact of human resource management practices on turnover, productivity, and corporate financial performance. Academy of Management Journal, 38: $635-672$.

Janz, T., Hellervik, L., \& Gilmore, D. 1986. Behavior Description Interviewing: New Accurate, and Cost Effective, Boston, MA: Allyn \& Bacon.

Jackson, S.E. \& Schuler, R.S. 1995. Understanding human resource management in the context of organizations and their environments. Annual Review of Psychology, 46: 237264.

Jackson, S.E., Schuler, R.S. \& Rivero, J.C. 1989. Organizational characteristics as predictors of personnel practices. Personnel Psychology, 42: 727-786.

Johns, G. 1993. Constraints on the adoption of psychology based personnel practices: Lesson from organizational innovation. Personnel Psychology, 46: 569-592.

Kahneman, D., Slovic, P. \& Tversky, A. 1982. Judgement under Uncertainty: Heuristics and Biases. Cambridge, MA: Cambridge University Press.

Katz, D. \& Kahn, R. 1978. The social psychology of organizations. New York, NY: John Wiley \& Sons.

Kerr, J. 1982. Assigning manages on the basis of the life cycle. Journal of Business Strategy, 2(4): 58-65.

Kerr, J.L. \& Jackofsky, E.F. 1989. Aligning managers with strategies: Management development versus selection. Strategic Management Journal, 10: 157-170.

Kochan, T., \& Osterman, P. 1994. The Mutual Gains Enterprise: Forging a winning partnership among labor, management and government. Boston, Harvard Business School Press.

Kochan, T., Smith, M. Wells, J., \& Rebitzer, J. 1994. Human resource strategies and contingent workers: The case of safety and Health in the petrochemical industry. Human Resource Management, 33: 55-77.

Lado, A.A. \& Wilson, M.C. 1994. Human resource systems and sustained competitive advantage: A competency-based perspective. Academy of Management Review, 19(4): 699-727.

Latham, G., \& Wexley, K. 1981. Increasing productivity through performance appraisal, Reading, MA: Addison-Wesley.

Ledford, G. 1995. Paying for the skills, knowledge, and competencies of knowledge workers. Compensation and Benefits Review, 27(4): 55-62.

Lengnick-Hall, C.A. \& Lengnick-Hall, M.L. 1988. Strategic human resources management: A review of the literature and a proposed typology. Academy of Management Review, 13(3): 454-470. 
MacDuffie, J. (1995). Human resource bundles and manufacturing performance: Organizational logic and flexible production systems in the world auto industry. Industrial and Labor Relations Review, 48, 197-221.

March, J. \& Simon, H. 1958. Organizations. New York, NY: Wiley.

Martell, K. \& Carroll, S.J. 1995. How strategic is HRM? Human Resource Management, 34(2): 253-267.

Meyer, J. \& Rowan, E. 1977. Institutionalized organizations: Formal structure as myth and ceremony. American Journal of Sociology, 83: 340-363.

Michel, J. \& Hambrick, D. 1992. Diversification posture and top management team characteristics. Academy of Management Journal, 35: 9-37.

Miles, R.E. \& Snow, C.C. 1978. Designing strategic human resources systems. Organizational Dynamics, 36-52.

Milliman, J., Von Glinow, M.A. \& Nathan, M. 1991. Organizational life cycles and strategic international human resource management in multinational companies: Implications for congruence theory. Academy of Management Review, 16(2): 318-339.

Mintzberg, H. (1994). The fall and rise of strategic planning. Harvard Business Review, (January/February): 107-114.

Montemayor, E. 1996. Congruence between pay policy and competitive strategy in highperforming firms. Journal of Management, 22: 889-908.

Mueller, F. 1996. Human resources as strategic assets: An evolutionary resource-based theory. Journal of Management Studies, 33(6): 757-785.

Nadler, D., \& Tushman, M. 1980. A diagnostic model for organizational behavior. In J.R. Hackman, E.E. Lawler, and L.W. Porter (eds.), Perspectives on Behavior in Organizations, pp 83-100, New York: McGraw-Hill.

Noe, R., Wilk, S., Mullen, E, \& Wanek, J. 1997. Employee development: construct validation issues. In J. K. Ford (Ed.), Improving training effectiveness in work organizations, pp 153-189. Lawrence Erlbaum: Mahweh, NJ.

Olian, J.D. \& Rynes, S.L. 1984. Organizational staffing: Integrating practice with strategy. Industrial Relations, 23(2): 170-183.

Oliver, C. 1997. Sustained competitive advantage: Combining institutional and resource-based views. Strategic Management Journal, 18(9): 697-713.

Peterson, R. 1981. Entrepreneurship and organization. In P.C. Nystrom and W.H. Starbuck (Eds.), Handbook of organizational design, (Vol. 1, pp 65-83). New York: Oxford University Press.

Pfeffer, J., 1994. Competitive Advantage Through People, Boston: Harvard Business Review Press. 
Prahalad, 1983. Developing strategic capability: An agenda for top management. Human Resource Management, 22: 237-254.

Purcell, E., Campion, M., and Gaylord, S. 1980. Structured interviewing: Avoiding selection problems. Personnel Journal.

Quick, J. (1992). Crafting an organizational culture: Herb's hand at Southwest. Organizational Dynamics, 21, 45-56.

Sanchez, R. 1995. Strategic flexibility in product competition. Strategic Management Journal, 16:135-159.

Schank, R. \& Abelson, R. 1977. Scripts, Plans, goals, and understanding. New York, NY: Halsted.

Schuler, R.S. 1992. Strategic human resources management: Linking the people with the strategic needs of the business. Organizational Dynamics, 18-32.

Schuler, R.S. \& Jackson, S. 1987. Linking competitive strategies with human resource management practices. Academy of Management Executive, 1: 207-219.

Schuler, R.S. \& MacMillan, I.C. 1984. Gaining competitive advantage through human resource management practices. Human Resource Management, 23(3): 241-255.

Scott, W.R. 1987. The adolescence of insitutional theory. Administrative Science Quarterly, 32 : 493-511.

Schneider, B. 1987. The people make the place. Personnel Pscyhology, 40: 437-454.

Snell, S.A. 1992. Control theory in strategic human resource management: The mediating effect of administrative information. Academy of Management Journal, 35: 292-327.

Snell, S.A. \& Dean, J.W., Jr. 1992. Integrated manufacturing and human resource management: A human capital perspective. Academy of Management Journal, 35: 467504.

Snell, S.A. \& Dean, J.W., Jr. 1994. Strategic compensation for integrated manufacturing: The moderating effects of jobs and organizational inertia. Academy of Management Journal, 37: 1109-1140.

Snell, S.A. \& Youndt, M.A. 1995. Human resource management and firm performance: Testing a contingency model of executive controls. Journal of Management, 21: 711738.

Snell, S.A., Youndt, M.A. \& Wright, P.M. 1996. Establishing a framework for research in strategic human resource management: Merging resource theory and organizational learning. In G.R. Ferris (Ed.) Research in Personnel and Human Resources Management, Vol 14. 
Snow, C.C. \& Snell, S.A. 1992. Staffing as strategy. In N. Schmitt, W. Borman \& Associates (Eds.) Personnel Selection in Organizations. San Francisco, CA: Jossey-Bass.

Teece, D., Pisano, G., \& Shuen, A. 1997. Dynamic capabilities and strategic management. Strategic Management Journal, 18:7, 509-533.

Truss, C. \& Gratton, L. 1994. Strategic human resource management: A conceptual approach. International Journal of Human Resource Management, 5(3): 663-686.

Ulrich, D. \& Lake, D. 1990. Organizational capability: Competing from the Inside/Out. New York, NY: Wiley.

Venkatraman, N. 1989. The concept of fit in strategy research: Toward a verbal and statistical correspondence. Academy of Management Review, 14: 423-444.

Weick, K. 1979. The social psychology of organizing. Boston, MA: Addison-Wesley.

Wolfe, R.A. 1995. Human resource management innovations: Determinants of their adoption and implementation. Human Resource Management, 34(2): 313-327.

Wiersma, M., \& Bantel, K. 1992. Top management team demongraphy and corporate strategic change. Academy of Management Journal, 35: 91-121.

Wright, P.M. (1994). Goal setting and monetary incentives: Motivational tools that can work too well. Compensation and Benefits Review, 26, 3 (May/June), 41-49.

Wright, P.M. \& McMahan, G.C. 1992. Theoretical perspectives for strategic human resource management. Journal of Management, 18(2): 295-320.

Wright, P.M. \& Snell, S.A. 1991. Toward an integrative view of strategic human resource management. Human Resource Management Review, 1(3): 203-225.

Wright, P.M., McMahan, G.C. \& McWilliams, A. 1994. Human resources and sustained competitive advantage: A resource-based perspective. International Journal of Human Resource Management, 5(2): 301-326.

Wright, P.M., McMahan, G.C., Snell, S.A., \& Gerhart, B. 1997. Strategic Human Resource Management: Building Human Capital and Organizational Capability, Technical report.

Wright, P. M., McCormick, B., Sherman, W.S., \& McMahan, G. (1995). The impact of HR practices on petrochemical refinery performance. Paper presented at the 1995 Academy of Management meeting.

Wright, P.M., Smart, D. \& McMahan, G.C. 1995. On the integration of strategy and human resources: An investigation of the match between human resources and strategy among NCAA basketball teams. Academy of Management Journal, 38:L 1052-1074.

Youndt, M., Snell, S.A., Dean, J.W., Jr. \& Lepak, D.P. 1996. Human resource management, manufacturing strategy, and firm performance. Academy of Management Journal, 39: 836-866. 